University of Nebraska - Lincoln

DigitalCommons@University of Nebraska - Lincoln

$9-2011$

\title{
Time course of prepulse inhibition disruption induced by dopamine agonists and NMDA antagonists: Effects of drug administration regimen
}

\author{
Ming Li \\ University of Nebraska-Lincoln, mli2@unl.edu \\ Wei He \\ University of Nebraska-Lincoln \\ Jing Chen \\ Shanghai Jiaotong University
}

Follow this and additional works at: https://digitalcommons.unl.edu/psychfacpub

Part of the Psychiatry and Psychology Commons

$\mathrm{Li}$, Ming; He, Wei; and Chen, Jing, "Time course of prepulse inhibition disruption induced by dopamine agonists and NMDA antagonists: Effects of drug administration regimen" (2011). Faculty Publications, Department of Psychology. 585.

https://digitalcommons.unl.edu/psychfacpub/585

This Article is brought to you for free and open access by the Psychology, Department of at DigitalCommons@University of Nebraska - Lincoln. It has been accepted for inclusion in Faculty Publications, Department of Psychology by an authorized administrator of DigitalCommons@University of Nebraska - Lincoln. 


\title{
Time course of prepulse inhibition disruption induced by dopamine agonists and NMDA antagonists: Effects of drug administration regimen
}

\author{
Ming Li, ${ }^{1}$ Wei He, ${ }^{1}$ and Jing Chen ${ }^{1,2}$ \\ 1. Department of Psychology, University of Nebraska-Lincoln, Lincoln, NE 68588-0308, USA \\ 2. Shanghai Mental Health Center, Shanghai Jiaotong University, 6oo South Wanping, Xuhui District, \\ Shanghai, PR China \\ Corresponding author - M. Li, 238 Burnett Hall, Department of Psychology, University of Nebraska-Lincoln, \\ Lincoln, NE68588-0308, USA; tel 402472 3144, email mli2@unl.edu
}

\begin{abstract}
Prepulse inhibition (PPI) of acoustic startle response is impaired in patients with schizophrenia and in animals acutely treated with dopamine agonists and NMDA antagonists. In this study, we investigated the time course of PPI disruption induced by repeated amphetamine, quinpirole, phencyclidine (PCP), and dizocilpine (MK-8o1) treatment. We focused on how PPI disruption development was influenced by drug administration regimens, comparing a constant versus an escalating dosing regimen. Male Sprague-Dawley rats were repeatedly treated with amphetamine $(1.25-5.0 \mathrm{mg} / \mathrm{kg}$, or constant $5.0 \mathrm{mg} / \mathrm{kg}$, sc), PCP (o.50-2.0 mg/kg, or constant 0.5, 1.0 or $2.0 \mathrm{mg} / \mathrm{kg}$, sc), quinpirole (o.03-0.12 mg/kg, or constant $0.12 \mathrm{mg} / \mathrm{kg}, \mathrm{sc}), \mathrm{MK}-801$ (o.025-0.10 mg/kg, or constant $0.10 \mathrm{mg} / \mathrm{kg}$, sc) or vehicle (saline) and tested for PPI once daily for 6 consecutive days. When amphetamine $5.0 \mathrm{mg} / \mathrm{kg}$ or quinpirole $0.12 \mathrm{mg} / \mathrm{kg}$ was administrated on a constant dosing schedule, both drugs disrupted PPI upon acute administration, but had no effect after repeated treatment and testing (days 2-5). However, when amphetamine $5.0 \mathrm{mg} / \mathrm{kg}$ or quinpirole $0.12 \mathrm{mg} / \mathrm{kg}$ was preceded by two lower doses in an escalating dosing regimen, both drugs still disrupted PPI on days 5 and 6 when the constant amphetamine and quinpirole had no effect. For PCP and MK-8o1, repeated treatment under both regimens produced a stable and persistent disruption of PPI. Startle magnitude increased progressively and dose-dependently under both regimens for all drugs except for quinpirole, which caused a decrease. These results suggest that the drug dosing schedule, rather than the absolute amount of drug that an animal receives, has a greater impact on the development of PPI-disruptive effect of dopamine agonists than NMDA antagonists. Thus, in order to mimic the emerging process of PPI deficit with dopamine agonists, an escalating dosing regimen should be used.
\end{abstract}

Keywords: prepulse inhibition of acoustic startle, repeated amphetamine treatment, repeated phencyclidine treatment, quinpirole, dizocilpine (MK-8o1), sensitization effect, tolerance effect

\section{Introduction}

Clinical studies suggest that repeated intermittent exposure to dopamine agonists or releasers such as amphetamine and cocaine and non-competitive NMDA receptor antagonists such as ketamine and phencyclidine (PCP) can induce psychotic symptoms very similar to those observed in patients with schizophrenia (Bell, 1965; Janowsky and Risch, 1979; Javitt and Zukin, 1991). These drug-induced symptoms often emerge gradually and are progressively worsened with repeated drug exposure over a period of time (Ellinwood et al., 1973; Griffith et al., 1972). They are most often observed following a chronic escalating pattern of drug exposure (Angrist, 1994; Simon et al., 2002). This temporal feature is often modeled in animals by repeatedly treating them with psychotomimetic drugs and then examining the progressive increase in the sensitivity of an animal's response to the psychotogenic properties of drugs (Martinez et al., 2005; Nestler, 2001; Robinson and Becker, 1986), most noticeably, behavioral sensitization in the forms of locomotor activity and stereotypy (Segal et al., 1981; Segal and Mandell, 1974).
One issue with psychomotor sensitization and stereotypy as behavioral indices of schizophrenic symptoms is that they are not essential features of schizophrenia and do not seem to capture the emotional, cognitive, and perceptual disturbances that characterize schizophrenic disorders. Other behavioral abnormalities induced by repeated psychotomimetic drug treatment, such as disruption of prepulse inhibition (PPI) of acoustic startle response (ASR), may provide a better model for drug-induced psychosis or even idiopathic schizophrenia (Braff et al., 2001). PPI refers to the phenomenon of a reduction in the startle magnitude when the startling stimulus is preceded by a low-intensity prepulse. It has been widely used as a translational model of schizophrenia (Geyer and Braff, 1987; Swerdlow et al., 2008) which measures the sensorimotor gating ability, a pre-attentive information processing mechanism that is putatively disrupted in patients with schizophrenia and is thought to contribute to their sensory flooding and cognitive fragmentation (Braff and Geyer, 1990; Swerdlow et al., 2000). Animals treated with acute amphetamine, quinpirole (a $\mathrm{D}_{2 / 2}$ agonist), PCP or MK-801 (a NMDA antagonist) also exhibit PPI deficits (Culm and Hammer, 2004; Mansbach and Geyer, 
1989; Mansbach et al., 1988; Schwabe et al., 2005). However, it is not clear whether repeated treatment with these drugs induces a persistent disruption of PPI. So far, the evidence is inconclusive (Geyer et al., 2001). Sensitization (a progressive increase in PPIdisruption), tolerance (a progressive decrease in PPI-disruption), and no change in PPI have all been reported (Culm and Hammer, 2004; Mansbach et al., 1988; Martin-Iverson, 1999; Schulz et al., 2001; Schwabe et al., 2005).

The paradigm used to administer psychotomimetic drugs is an extremely important variable to consider in evaluating druginduced behavioral sensitization phenomena (Fletcher et al., 2005; Robinson and Becker, 1986; Tenn et al., 2005). The abovementioned conflicting reports may be due to differences in the treatment paradigms used, including drug doses, number of drug administrations, routes and treatment schedule, as well as the PPI testing schedule. In the present study, we sought to explore under what condition repeated treatment of amphetamine, quinpirole, PCP and MK-801 could produce a persistent disruption of PPI. We examined two dosing regimens. After habituation and baseline saline PPI tests were conducted, rats were treated under either a constant dosing regimen or an escalating dosing regimen for 6 consecutive days and their PPIs were tested daily. For amphetamine and quinpirole, we found that the constant dosing regimen produced an acute disruption of PPI. But with repeated treatment and testing, both drugs no longer disrupted PPI. In contrast, amphetamine and quinpirole administrated in an escalating dosing regimen produced PPI disruption even after repeated treatment and testing. For PCP and MK8o1, both treatment regimens produced a stable and persistent disruption of PPI at the dose range tested in this study (0.50$2.0 \mathrm{mg} / \mathrm{kg}$ for PCP and $0.025^{-0.10} \mathrm{mg} / \mathrm{kg}$ for MK-801). Our results thus emphasize the importance of drug administration paradigms for different psychotomimetic drugs, rather than the amount of drugs, in producing different patterns of psychopharmacological effects on PPI. They also suggest that for dopamine agonists or indirect agonists, an escalating dosing regimen may be more appropriate in inducing behavioral changes in rats with close resemblance to symptoms of schizophrenia.

\section{Materials and methods}

\subsection{Animals}

Male Sprague-Dawley rats (250-275 g upon arrival, Charles River, Portage, MI) were housed two per cage, in $48.3 \mathrm{~cm} \times 26.7 \mathrm{~cm} \times 20.3 \mathrm{~cm}$ transparent polycarbonate cages under 12-h light/dark conditions (light on between 6:00 am and 6:0o $\mathrm{pm}$ ). Room temperature was maintained at $22^{\circ} \pm 1^{\circ}$ with a relative humidity of $40-60 \%$. Food and water was available ad libitum. Animals were allowed at least 1 week of habituation to the animal facility before being used in experiments. All procedures were approved by the animal care committee at the University of Nebraska-Lincoln.

\subsection{Prepulse inhibition of acoustic startle reflex apparatus}

The prepulse inhibition test was performed using six Startle Monitor Systems (Kinder Scientific, Julian, CA). Each system, controlled by a PC, was housed in a compact sound attenuation cabinet $(36 \mathrm{~cm}$ wide $\times 28 \mathrm{~cm}$ deep $\times 50 \mathrm{~cm}$ high). A speaker (diameter: $11 \mathrm{~cm}$ ) mounted on the cabinet's ceiling was used to generate acoustic stimuli $(70 \mathrm{~dB}-120 \mathrm{~dB})$. The startle response was measured by a piezoelectric sensing platform on the floor, which was calibrated daily. During testing, rats were placed in a rectangular box made of transparent Plexiglas $(19 \mathrm{~cm}$ wide $\times 9.8 \mathrm{~cm}$ deep $\times 14.6$ high) with an adjustable ceiling positioned atop the box, providing only limited restraint while prohibiting ambulation.

\subsection{Drugs}

The injection solutions of d-amphetamine sulfate (AMPH, SigmaAldrich, St. Louis, MO), quinpirole (QUI, Sigma-Aldrich, St. Louis, MO), (+)-MK-801 Hydrogen Maleate (a gift from NIMH Chemical Synthesis and Drug Supply Program) and PCP hydrochloride (a gift from NIDA Chemical Synthesis and Drug Supply Program) were obtained by mixing drugs with $0.9 \%$ saline. All injections were administrated subcutaneously at a volume of $1 \mathrm{ml} / \mathrm{kg}$.

\subsection{Experiment 1: Effects of repeated amphetamine (1.25- 5.0) or PCP (0.5-2.0) treatment on an escalating dose regi- men or a constant dose regimen on prepulse inhibition}

The entire experiment consisted of the following three phases, each separated by 1 day.

2.4.1. Phase 1: Handling and PPI habituation (2 days)

Rats $(\mathrm{n}=60)$ were first handled individually for 2 days for approximately 2 min each day to minimize stress during behavioral testing. On the first handling day, the rats were acclimated to the prepulse inhibition apparatus for $10 \mathrm{~min}$. On the second handling day, the rats were also habituated to the PPI test procedure, which was adapted from Culm and Hammer (2004). The PPI session lasted approximately $18 \mathrm{~min}$ and began with a 5 minute period of $70 \mathrm{~dB}$ background noise (which continued throughout the duration of the session) followed by four different trial types: PULSE ALONE trials and three types of PREPULSE + PULSE trials, which consisted of a $20 \mathrm{~ms} 73,76$, or $82 \mathrm{~dB}$ prepulse $(3,6$, and $12 \mathrm{~dB}$ above background) followed $100 \mathrm{~ms}$ later by a $120 \mathrm{~dB}$ pulse. Each session was divided into 4 blocks. Blocks 1 and 4 were identical, each consisting of 4 PULSE ALONE trials. Blocks 2 and 3 were also identical and each consisted of 8 PULSE ALONE trials and 5 of each PREPULSE + PULSE trial type. A total of 54 trials were presented during each test session. Trials within each block were presented in a pseudorandom order and were separated by a variable inter-trial interval averaging $15 \mathrm{~s}$ (ranging from 9 to $21 \mathrm{~s}$ ). Startle magnitude was defined as the maximum force (measured in Newtons) applied by the rat to the startle apparatus recorded over a period of $100 \mathrm{~ms}$ beginning at the onset of the pulse stimulus. Startle responses from testing blocks 2 and 3 were used to calculate percent prepulse inhibition (\%PPI) for each acoustic prepulse trial type:

$\% \mathrm{PPI}=100-\left[\left(\frac{\text { average startle response to PREPULSE }+ \text { PULSE trials }}{\text { average startle response to PULSE ALONE trials }}\right) \times 100\right]$

2.4.2. Phase 2: PPI testing under vehicle (1 day)

One day after the second habituation day, rats were injected subcutaneously with saline and tested for PPI 10 min after injection. The averaged \%PPI at three prepulse levels $(73,76$, and $82 \mathrm{~dB})$ on this day was used to create matched groups such that all groups had comparable baseline PPI performance before the drug tests.

2.4.3. Phase 3: Repeated PPI testing under drug (6 days)

Five groups ( $n=12$ /group) were formed on the basis of their PPI on the saline day: VEH (saline, sc), AMPH-constant $(5.0 \mathrm{mg} /$ $\mathrm{kg}, \mathrm{sc}$ ), AMPH-escalating (1.25-5.0 mg/kg, sc), PCP-constant (2.0 mg/kg, sc), PCP-escalating (0.5-2.0 mg/kg, sc). During each daily test, rats were injected with either saline, AMPH or PCP 10 min prior to being placed into the PPI boxes. Table 1 depicts the daily injection schedule.

\subsection{Experiment 2: Effects of repeated PCP (0.5 or $1.0 \mathrm{mg} / \mathrm{kg})$ treatment on a constant dose regimen on prepulse inhibition}

Results from Experiment 1 showed that PCP (2.0 mg/kg) administrated under the constant dosing schedule maintained its 
Table 1. Groups and drug treatment for Experiment 1 (All drugs were administrated subcutaneously at a volume of $1 \mathrm{ml} / \mathrm{kg}$ ).

\begin{tabular}{llllllll}
\hline Group & $\mathrm{N}$ & $\mathrm{D} 1$ & $\mathrm{D} 2$ & $\mathrm{D} 3$ & $\mathrm{D} 4$ & $\mathrm{D} 5$ & $\mathrm{D} 6$ \\
\hline Vehicle & 12 & SAL & SAL & SAL & SAL & SAL & SAL \\
AMPH constant & 12 & 5.0 & 5.0 & 5.0 & 5.0 & 5.0 & 5.0 \\
AMPH escalating & 12 & 1.25 & 1.25 & 2.5 & 2.5 & 5.0 & 5.0 \\
PCP constant & 12 & 2.0 & 2.0 & 2.0 & 2.0 & 2.0 & 2.0 \\
PCP escalating & 12 & 0.5 & 0.5 & 1.0 & 1.0 & 2.0 & 2.0 \\
\hline
\end{tabular}

disruption. Experiment 2 further examined this issue using two lower doses of PCP (0.5 and $1.0 \mathrm{mg} / \mathrm{kg}$ ) and also addressed the potential floor effect (PCP at $2.0 \mathrm{mg} / \mathrm{kg}$ already caused a maximal PPI disruption, leaving no room to show a sensitization effect). Two lower doses of PCP (o.5 and $1.0 \mathrm{mg} / \mathrm{kg}$ ) were used. The basic procedure was identical to that of Experiment 1. Based on the PPI performance on the saline day, 36 rats were matched and assigned to three groups ( $\mathrm{n}=12$ /group): VEH (saline), $\mathrm{PCP} 0.5 \mathrm{mg} / \mathrm{kg}$ and PCP $1.0 \mathrm{mg} / \mathrm{kg}$, and their PPIs were tested for 6 days.

\subsection{Experiment 3: Effects of repeated quinpirole (o.o3-0.12) or MK-801 (o.025-0.1) treatment on an escalating dose regi- men or a constant dose regimen on prepulse inhibition}

Quinpirole and MK-8o1 are two drugs that are often used in the study of animal models of schizophrenia. Like amphetamine and PCP, both drugs affect dopamine and NMDA-mediated neurotransmission and acutely disrupt PPI, but their repeated effects on PPI are less clear. This experiment investigated the effects of repeated administration of quinpirole and MK-801 under the two dosing schedules on PPI. We were interested in whether the regimen effect with amphetamine and PCP could also be found with quinpirole and MK-801. The basic procedure was identical to that of Experiment 1. Sixty rats were matched and assigned to five groups ( $\mathrm{n}=12$ /group): VEH (saline), QUI-constant (o.12 mg/ $\mathrm{kg}, \mathrm{sc}$ ), QUI-escalating (o.03-0.12 mg/kg, sc), MK-801-constant (o.10 mg/kg, sc), MK-801-escalating (0.025-0.10 mg/kg, sc). PPI was tested for 6 days. During each daily test, rats were injected with either saline or one of the drugs 10 min prior to being placed into the PPI boxes. Table 2 depicts the daily injection schedule.

\subsection{Statistical analysis}

Percent PPI data for the 6 drug days were presented separately for three prepulse intensities (e.g. 73, 76 and $82 \mathrm{~dB}$ ). The magnitude of the acoustic startle reflex (ASR) was calculated as the average response on the PULSE ALONE trials, excluding the first and last blocks of 4 PULSE ALONE trials. Percent PPI and ASR data from the drug test period were first analyzed using SPSS (v19) repeated measures ANOVAs with drug treatment (i.e. vehicle, constant or escalating) as a between-subjects factor and test day (i.e. 6) as a within-subjects factor. For PPI data, another within-subjects factor (i.e. 3 prepulse levels) was also included in the analysis. If necessary, one-way ANOVAs followed by post hoc LSD tests were used to identify between-group differences on specific days, and paired-samples t tests were used to identify the temporal changes of treatment effects from day 1 to day 6. Data for each drug (e.g. AMPH and PCP) were analyzed separately because we were primarily interested in the effects of

Table 2. Groups and drug treatment for Experiment 3 (All drugs were administrated subcutaneously at a volume of $1 \mathrm{ml} / \mathrm{kg}$ ).

\begin{tabular}{|c|c|c|c|c|c|c|c|}
\hline Group & No. & Drug & reatme & t (Day & 1-6) & & \\
\hline Vehicle & 12 & SAL & SAL & SAL & SAL & SAL & SAL \\
\hline QUI constant & 12 & 0.12 & 0.12 & 0.12 & 0.12 & 0.12 & 0.12 \\
\hline QUI escalating & 12 & 0.03 & 0.03 & 0.06 & 0.06 & 0.12 & 0.12 \\
\hline MK-8o1 constant & 12 & 0.10 & 0.10 & 0.10 & 0.10 & 0.10 & 0.10 \\
\hline MK-8o1 escalating & 12 & 0.025 & 0.025 & 0.05 & 0.05 & 0.10 & 0.10 \\
\hline
\end{tabular}

dosing regimen and less interested in differences between drugs. For all analyses, $\mathrm{P}<0.05$ was considered statistically significant.

\section{Results \\ 3.1. Experiment 1: Effects of repeated amphetamine (1.25- 5.0) or PCP (0.5-2.0) treatment on an escalating dose regi- men or a constant dose regimen on prepulse inhibition}

Due to equipment malfunction on the last drug test day, data for 12 rats were lost (1 vehicle, 3 AMPH-constant, 3 AMPH-escalating, 2 PCP-constant and 3 PCP-escalating rats). The following analysis was based on the data from the remaining 48 rats ( $\mathrm{n}=9^{-11}$ /group).

3.1.1. $P P I$

As expected, there was no group difference on the averaged percent PPI on the saline day $(\mathrm{F}(4,55)=0.08, \mathrm{P}=0.988$, data not shown). For amphetamine, analysis of PPI data from the 6 drug test days revealed a main effect of treatment $(\mathrm{F}(2,26)=4.249$, $\mathrm{P}=0.025)$, prepulse level $(\mathrm{F}(2,52)=366.66, \mathrm{P}<0.001)$ and $\mathrm{a}$ significant treatment $\times$ test day interaction $(\mathrm{F}(10,130)=3.472$, $\mathrm{P}<0.001)$. These results suggest that amphetamine disrupted PPI and the disruption varied in different treatment schedules and across the test days.

At all three prepulse intensity levels (Figure $1 \mathrm{~A}, \mathrm{~B}$ and $\mathrm{C}$ ), one-way ANOVA followed by LSD post hoc tests revealed that the AMPH-constant group had significantly lower PPIs than the other two groups only on day 1 (all Ps $<0.003$ ), indicating an acute PPI-disruptive effect of AMPH at $5.0 \mathrm{mg} / \mathrm{kg}$. In contrast, the AMPH-escalating group had significantly lower PPIs than the vehicle group primarily on day 5 and 6 at the $76 \mathrm{~dB}$ $(\mathrm{P}=0.014$, and 0.050$)$ and $82 \mathrm{~dB}$ levels $(\mathrm{P}=0.009$ and o.008). It also had a significantly lower PPI than the vehicle group at the $76 \mathrm{~dB}$ level on day $1(\mathrm{P}=0.011)$.

When PPIs on day 6 of drug testing were compared to those on day 1 , the vehicle and AMPH-escalating groups did not show any significant change in PPI at all three prepulse levels (all Ps > 0.105). In contrast, the AMPH-constant group had significantly higher PPIs on day 6 than on day 1 at the $73 \mathrm{~dB}(\mathrm{P}=0.007)$ and $82 \mathrm{~dB} \mathrm{lev-}$ els $(\mathrm{P}=0.033)$, indicating that repeated AMPH treatment at this constant dose induced a tolerance-like effect on PPI disruption.

For PCP, repeated measures ANOVA showed a main effect of treatment $(\mathrm{F}(2,27)=54.987, \mathrm{P}<0.001)$ and prepulse level $(\mathrm{F}(2,54)=359.939, \mathrm{P}<0.001)$. There was also a significant treatment $\times$ test day interaction $(\mathrm{F}(10,135)=1.932, \mathrm{P}=0.046)$, and a significant treatment $\times$ prepulse level interaction $(\mathrm{F}(4$, $54)=11.211, P<0.001)$. These results suggest that the disruptive effect of PCP on PPI varied under different treatment schedules and differed at different prepulse levels on different test days.

At the 73 and $76 \mathrm{~dB}$ prepulse intensity levels (Figure $2 \mathrm{~A}$ and B), one-way ANOVA followed by LSD post hoc tests revealed that both PCP groups had significantly lower PPIs than the vehicle group on every test day (all Ps $<$ o.035) except on day 3 when the difference between the PCP-escalating group and the vehicle group did not reach the significant level $(\mathrm{P}=0.059)$ at the $73 \mathrm{~dB}$ level. In addition, the PCP-constant group also had a significantly lower PPI than the PCP-escalating group on day 3 at the $73 \mathrm{~dB}$ prepulse level $(\mathrm{P}=0.010)$ and on day 4 at the $76 \mathrm{~dB}$ prepulse level $(\mathrm{P}=0.011)$. Similarly, at the $82 \mathrm{~dB}$ prepulse intensity level (Figure $2 \mathrm{C}$ ), both PCP groups had significantly lower PPIs than the vehicle group on all 6 test days (all Ps $<$ o.oo1). In addition, the PCP-constant group also had significantly lower PPIs than the $\mathrm{PCP}$-escalating group on day $3(\mathrm{P}<0.008)$ and day $4(\mathrm{P}<0.044)$.

Comparing day 1 versus day 6, neither the PCP-constant nor the PCP-escalating group showed any significant change in PPI at all three prepulse levels (all Ps $>0.176$ ), indicating that repeated PCP treatment under either treatment schedule produced a persistent PPI disruption. 

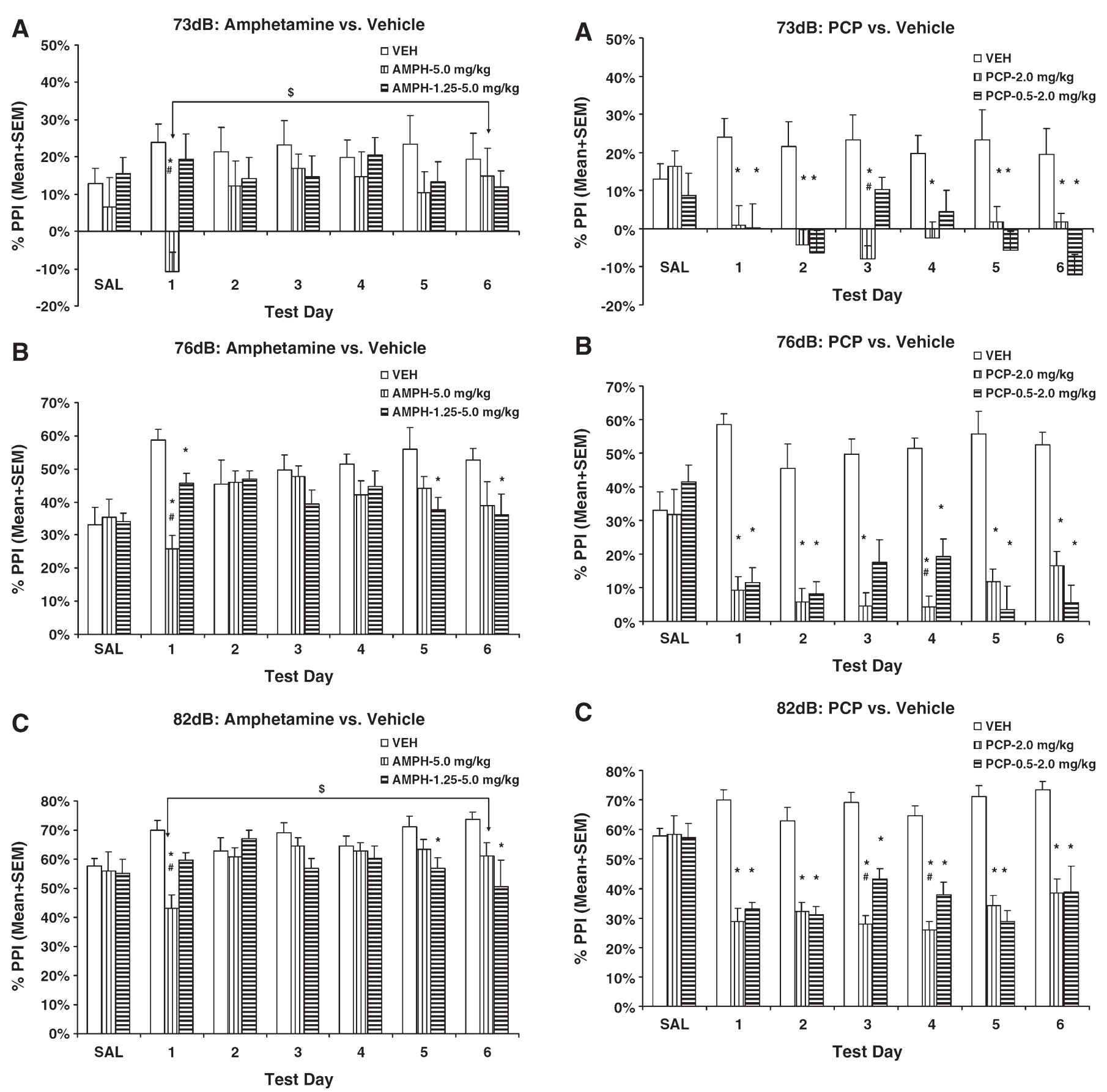

Figure 1. Effects of repeated administration of saline (VEH), constant amphetamine $\left(5.0 \mathrm{mg} / \mathrm{kg}\right.$ daily), or escalating amphetamine $\left(1.25^{-}\right.$ $5.0 \mathrm{mg} / \mathrm{kg}$ ) for 6 consecutive days on prepulse inhibition (PPI) at the $73 \mathrm{~dB}(\mathrm{~A}), 76 \mathrm{~dB}(\mathrm{~B})$, and $82 \mathrm{~dB}(\mathrm{C})$ prepulse levels. ${ }^{*} \mathrm{P}<0.05$ significantly different from the VEH group; \# $\mathrm{P}<0.05$ significantly different between the two amphetamine groups; $\$ \mathrm{P}<0.05$ significantly different between day 1 and day 6 .

\subsubsection{Acoustic startle response (ASR)}

For AMPH (Figure 3A), both AMPH regimens progressively enhanced startle amplitude over the treatment period. Repeated measures ANOVAs showed a main effect of test day $(\mathrm{F}(5$, $130)=7.520, P<0.001)$ and a significant treatment $\times$ test day interaction $(\mathrm{F}(10,130)=5.049, \mathrm{P}<0.001)$. One-way ANOVAs followed by LSD post hoc test on each test day showed that the AMPH-constant group had significantly higher startle amplitude than the vehicle group on days 3, 4, 5 and 6 (all Ps $<0.043$

Figure 2. Effects of repeated administration of saline (VEH), constant PCP (2.0 mg/kg daily), or escalating PCP $\left(0.5^{-2.0} \mathrm{mg} / \mathrm{kg}\right)$ for 6 consecutive days on prepulse inhibition (PPI) at the $73 \mathrm{~dB}(\mathrm{~A}), 76 \mathrm{~dB}(\mathrm{~B})$ and $82 \mathrm{~dB}(\mathrm{C})$ prepulse levels. ${ }^{*} \mathrm{P}<0.05$ significantly different from the VEH group; \# $\mathrm{P}<0.05$ significantly different between the two PCP groups.

vs. vehicle) (Figure $3 \mathrm{~A}$ ). The AMPH-escalating group had significantly higher startle amplitude than the vehicle group only on day $5(\mathrm{P}=0.010)$. For $\mathrm{PCP}$ (Figure $3 \mathrm{~B})$, repeated measures ANOVAs showed a main effect of treatment $(\mathrm{F}(2,27)=5.737$, $\mathrm{P}=0.008)$ and a significant treatment $\times$ test day interaction $(\mathrm{F}(10,135)=2.364, \mathrm{P}=0.013)$. One-way ANOVAs showed that both PCP groups significantly enhanced startle amplitude on all 6 test days (all Ps $<0.043 v s$. vehicle) with the exception of the $\mathrm{PCP}$-constant group on day $1(\mathrm{P}=0.154)$. 

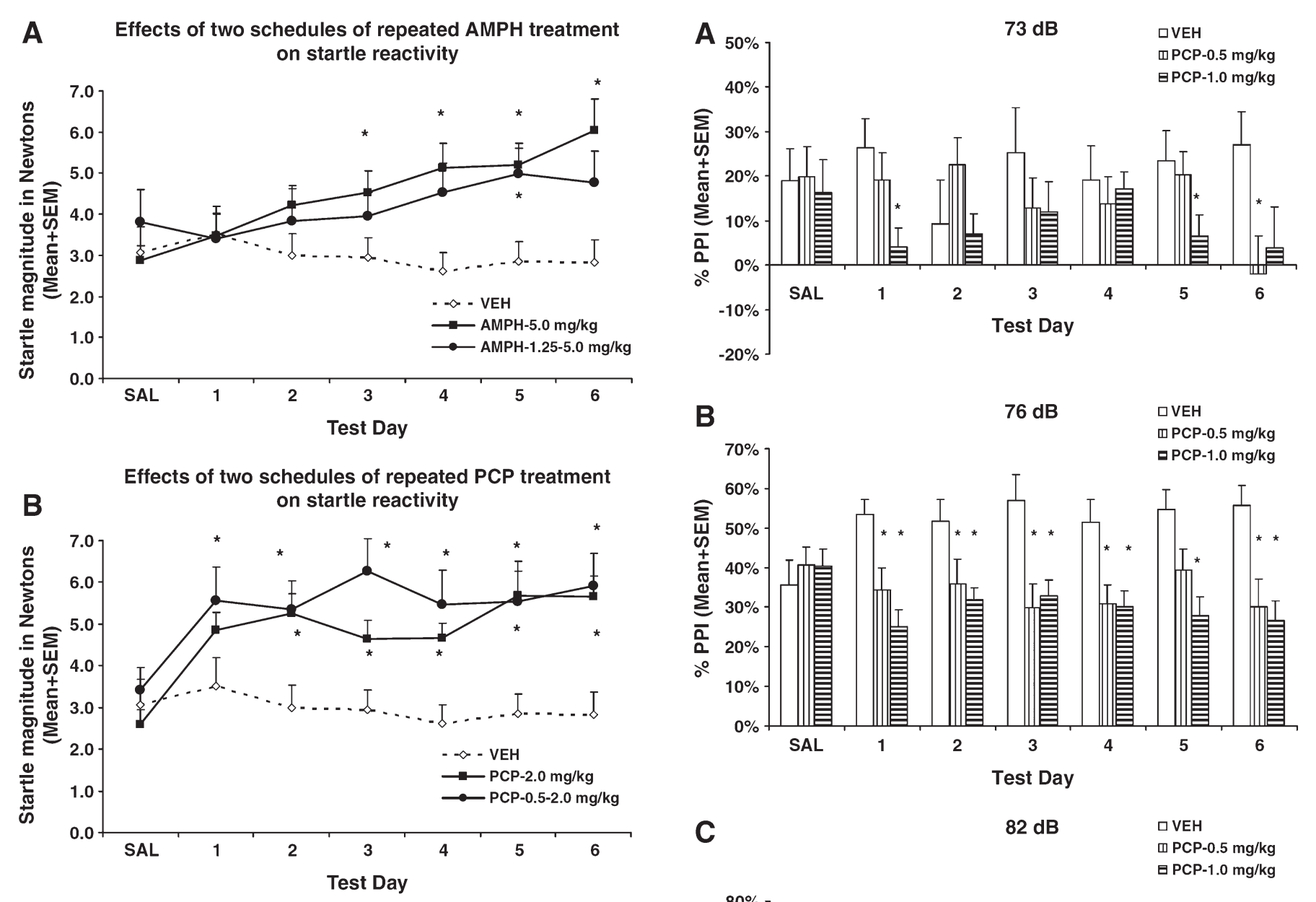

Figure 3. Effects of repeated administration of saline (VEH), constant amphetamine $(5.0 \mathrm{mg} / \mathrm{kg}$ daily), escalating amphetamine $(1.25-5.0 \mathrm{mg} /$ $\mathrm{kg}$ ) (A), constant PCP (2.0 mg/kg daily), or escalating PCP (o.5-2.0 mg/ $\mathrm{kg}$ ) for 6 consecutive days (B) on startle reactivity (e.g. startle responses on $120 \mathrm{~dB}$ white noise trials). Startle magnitude (mean \pm SEM) was calculated as the average response on the PULSE ALONE trials, excluding the first and last block of 4 PULSE ALONE trials. ${ }^{*} \mathrm{P}<0.05$ significantly different from the VEH group.

\subsection{Experiment 2: Effects of repeated PCP (o.5 or $1.0 \mathrm{mg} /$ kg) treatment on a constant dose regimen on prepulse inhibition}

Due to equipment malfunction on the 5 th drug test day, data for 4 rats were lost (2 vehicle rats and 2 PCP $0.5 \mathrm{mg} / \mathrm{kg}$ rats). The following analysis was based on the data from the remaining 32 rats ( $\mathrm{n}=10-12$ /group).

\subsubsection{PPI}

As expected, there was no group difference on the averaged percent PPI on the saline day $(\mathrm{F}(2,33)=0.074, \mathrm{P}=0.929)$. Analysis of PPI data from the 6 drug test days revealed a main effect of treatment $(\mathrm{F}(2,29)=11.853, \mathrm{P}<0.001)$ and prepulse level $(\mathrm{F}(2,58)=328.635$, $\mathrm{P}<0.001)$, but no main effect of test day $(\mathrm{F}(5,145)=0.832$, $\mathrm{P}=0.529)$, nor a significant treatment $\times$ test day interaction $(\mathrm{F}(10$, $145)=1.70, P=0.086)$. In addition, the treatment $\times$ prepulse level interaction was also not significant $(\mathrm{F}(4,58)=2.518, \mathrm{P}=0.051)$. Like the effect of PCP administered in the constant dosing regimen seen in Experiment 1, PCP at 0.5 and $1.0 \mathrm{mg} / \mathrm{kg}$ produced a persistent disruption of PPI across the test days.

At the $73 \mathrm{~dB}$ prepulse intensity level (Figure 4A), one-way ANOVA followed by LSD post hoc tests revealed that the PCP 1.o group had significantly lower PPIs than the vehicle group

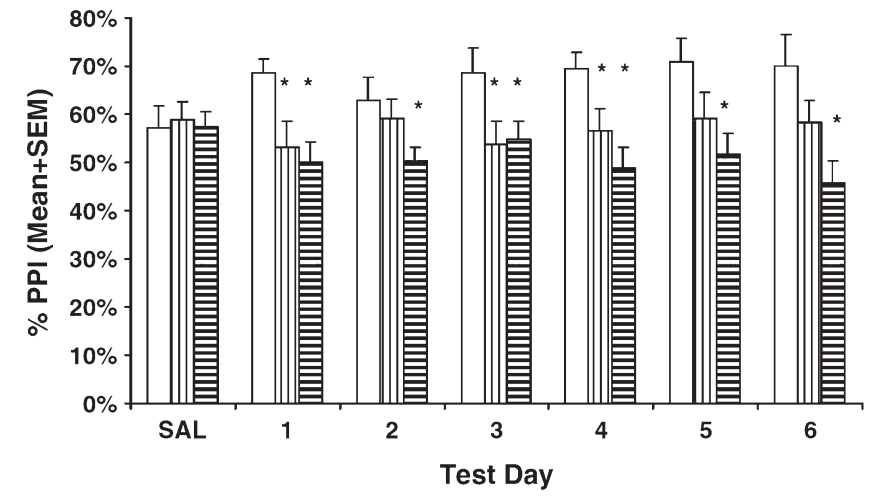

Figure 4. Effects of repeated administration of saline (VEH), PCP $(0.5 \mathrm{mg} / \mathrm{kg})$ or PCP $(1.0 \mathrm{mg} / \mathrm{kg})$ daily for 6 consecutive days on prepulse inhibition (PPI) at the $73 \mathrm{~dB}(\mathrm{~A}), 76 \mathrm{~dB}(\mathrm{~B})$ and $82 \mathrm{~dB}(\mathrm{C})$ prepulse levels. ${ }^{*} \mathrm{P}<0.05$ significantly different from the VEH group; \# $\mathrm{P}<0.05$ significantly different between the two PCP groups.

on day $1(\mathrm{P}=0.009)$ and day $5(\mathrm{P}=0.036)$, whereas the $\mathrm{PCP} 0.5$ group had significantly lower PPI only on day $6(\mathrm{P}=0.020)$. At the $76 \mathrm{~dB}$ prepulse intensity level (Figure $4 \mathrm{~B}$ ), both PCP groups had significantly lower PPIs than the vehicle group on every test day (all Ps < o.036) except on day 5 when the difference between the PCP 0.5 and vehicle group was only marginally significant $(\mathrm{P}=0.051)$. At the $82 \mathrm{~dB}$ prepulse intensity level (Figure $4 \mathrm{~B})$, the PCP 1.o group had significantly lower PPIs than the vehicle group on every test day (all Ps $<0.048$ ), whereas the PCP 0.5 group had significantly lower PPIs on days 1, 3, and 4 (all Ps $<0.042$ ).

The vehicle and PCP 1.0 groups did not show any significant change in PPI performance at all three prepulse levels from day 1 to day 6 (all Ps $>0.713$ ). The only significant change noticed was in 


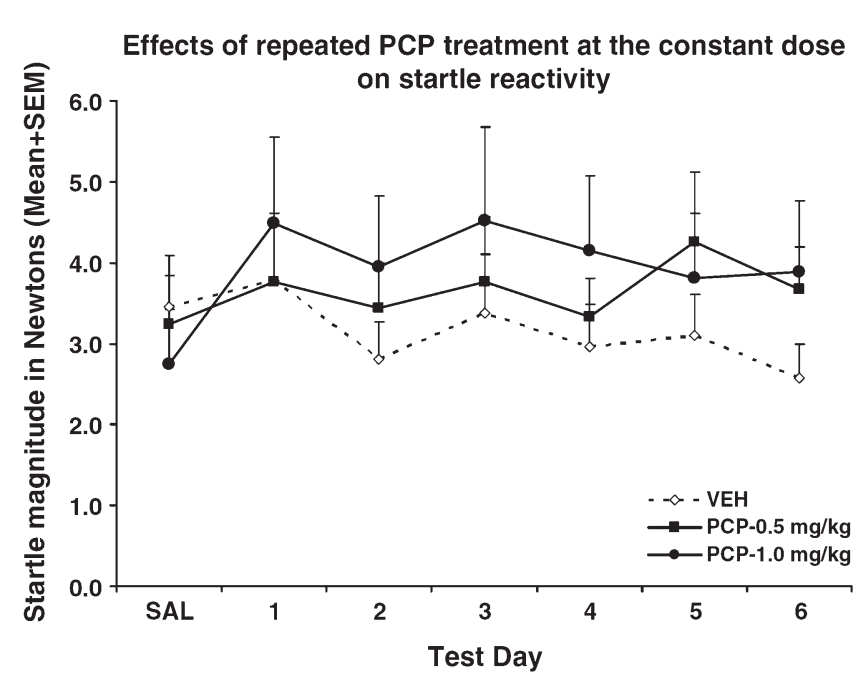

Figure 5. Effects of repeated administration of saline (VEH), PCP (o.5 mg/ $\mathrm{kg})$, or PCP $(1.0 \mathrm{mg} / \mathrm{kg})$ for 6 consecutive days on startle reactivity.

the PCP 0.5 group which had significantly lower PPI at the $73 \mathrm{~dB}$ level on day 6 than on day $1(\mathrm{P}=0.026)$. Collectively, these data indicate that repeated PCP treatment under the constant dosing schedules produced a stable and persistent PPI disruption.

\subsubsection{Acoustic startle response (ASR)}

There was a main effect of test day $(F(5,145)=3.982, P=0.002)$, but no main effect of PCP $(F(2,29)=0.288, P=0.752)$, or $\mathrm{PCP} \times$ test day interaction $(F(10,145)=1.251, P=0.264)$. One-way ANOVAs did not find any group difference on any test day (all $P \mathrm{~s}>0.453$, Figure 5).

\subsection{Experiment 3: Effects of repeated quinpirole (o.o3-o.12) or MK-801 (o.025-o.1) treatment on an escalating dose regi- men or a constant dose regimen on prepulse inhibition}

\subsubsection{PPI}

As expected, there was no group difference on the averaged percent PPI on the saline day $(\mathrm{F}(4,55)=0.085, \mathrm{P}=0.987$, data not shown). Quinpirole at $0.12 \mathrm{mg} / \mathrm{kg}$ disrupted PPI acutely. Analysis of PPI data from the 6 drug test days revealed a main effect of prepulse level $(\mathrm{F}(2,66)=332.485, \mathrm{P}<0.001)$ and a significant treatment $\times$ test day interaction $(\mathrm{F}(10,165)=2.177, \mathrm{P}=0.022)$, but no main effect of treatment $(\mathrm{F}(2,33)=2.424, \mathrm{P}=0.104)$. These results suggest that quinpirole disrupted PPI and that the disruption varied in different treatment schedules and across the test days.

At the $73 \mathrm{~dB}$ prepulse level (Figure 6A), one-way ANOVA followed by LSD post hoc tests revealed that the QUI-escalating group had significantly higher PPIs than the other two groups only on day 4 (all Ps < 0.031). At the $76 \mathrm{~dB}$ prepulse intensity level (Figure 6B), the QUI-constant group had a significantly lower PPI than the vehicle group $(\mathrm{P}=0.008)$ on day 1 , indicating an acute disruptive effect. It also had significantly lower PPIs than the QUIescalating group on day $1(\mathrm{P}=0.032)$, day $3(\mathrm{P}=0.023)$ and day $4(\mathrm{P}=0.037)$. Interestingly, the QUI-escalating group had a significantly higher PPI than the vehicle group on day $4(\mathrm{P}=0.011)$. At the $82 \mathrm{~dB}$ prepulse intensity level (Figure 6C), the QUI-constant group had a significantly lower PPI than the vehicle group $(\mathrm{P}=0.043)$ on day 1 . It also had significantly lower PPIs than the QUI-escalating group on day $1(P=0.030)$, day $2(P=0.013)$, day $3(\mathrm{P}=0.038)$ and day $4(\mathrm{P}=0.015)$. The QUI-escalating group had a significantly lower PPI than the vehicle group on the last day of testing $(\mathrm{P}=0.038)$, when the same dose of QUI in the constant schedule had no effect $(\mathrm{P}=0.146)$.
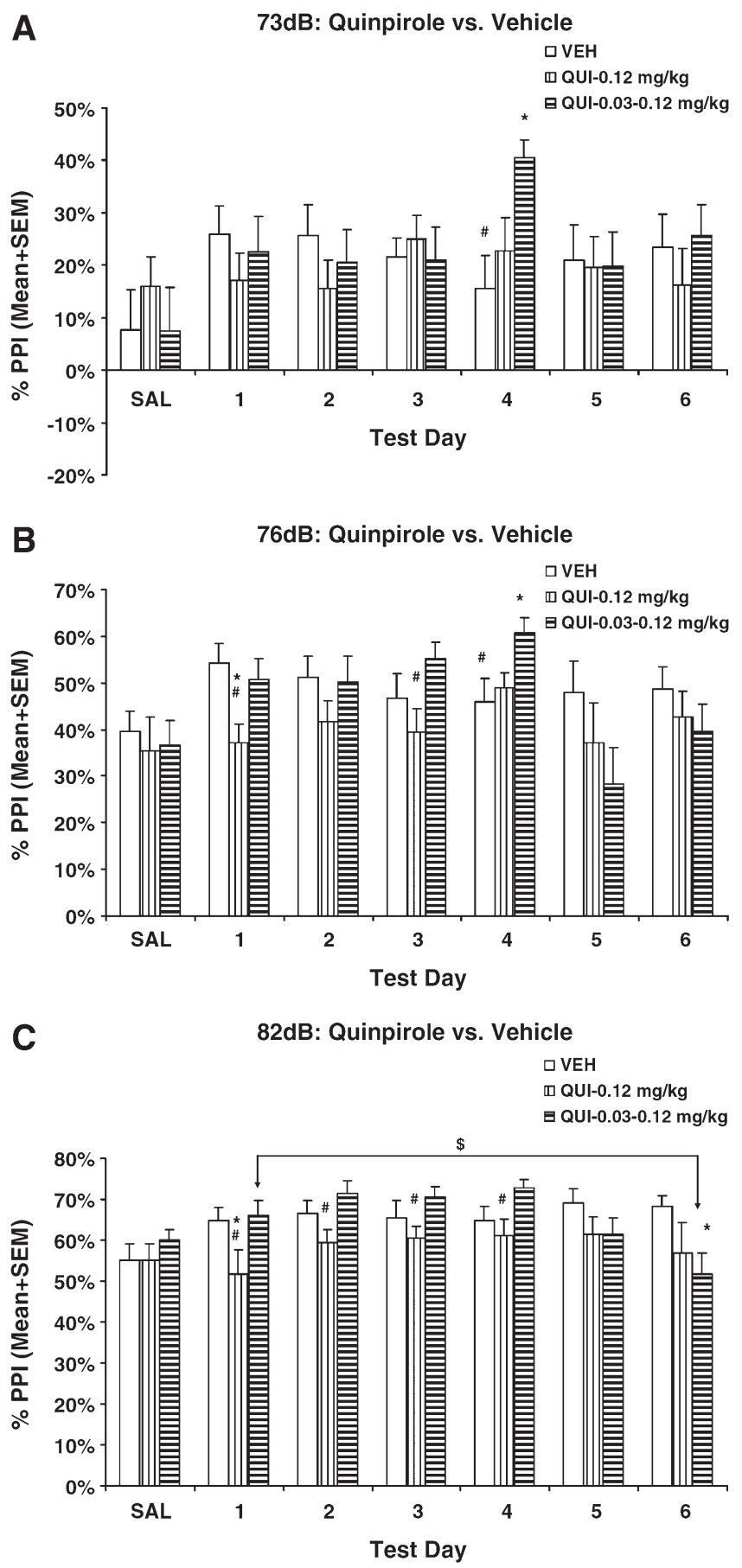

Figure 6. Effects of repeated administration of saline (VEH), constant quinpirole (0.12 mg/kg daily) or escalating quinpirole $(0.03-0.12 \mathrm{mg} / \mathrm{kg}$ ) for 6 consecutive days on prepulse inhibition (PPI) at the $73 \mathrm{~dB}(\mathrm{~A}), 76 \mathrm{~dB}$ (B) and $82 \mathrm{~dB}(\mathrm{C})$ prepulse levels. ${ }^{*} \mathrm{P}<0.05$ significantly different from the VEH group; \# $\mathrm{P}<0.05$ significantly different between the two quinpirole groups; $\$ \mathrm{P}<0.05$ significantly different between day 1 and day 6 .

In comparison to day 1 of drug testing, only the QUI-escalating group showed a significantly increased disruption of PPI at the $82 \mathrm{~dB}$ level on day $6(\mathrm{P}=0.035)$. None of the other groups showed any significant change (all Ps $>0.065$ ).

For MK-801, repeated measures ANOVA showed a main effect of treatment $(\mathrm{F}(2,33)=17.848, \mathrm{P}<0.001)$ and prepulse level $(\mathrm{F}(2,66)=360.912, \mathrm{P}<0.001)$. There was also a significant treatment $\times$ test day interaction $(\mathrm{F}(10,165)=2.605, \mathrm{P}=0.006)$. These 
results suggest that the disruptive effect of MK-801 on PPI varied under different treatment schedules and differed across the six test days.

At the $73 \mathrm{~dB}$ prepulse intensity level (Figure $7 \mathrm{~A}$ ), one-way ANOVA followed by LSD post hoc tests revealed that the MK8o1-constant group had significantly lower PPIs than the vehicle group on every test day (all Ps $<$ o.030) except on day 4 $(\mathrm{P}=0.058)$. In addition, the MK-801-constant group also had a significantly lower PPI than the MK-801-escalating group on day $3(\mathrm{P}=0.006)$. The MK-8o1-escalating group had significantly lower PPIs than the vehicle group on day $1(\mathrm{P}=0.003)$ and day $6(\mathrm{P}=0.023)$. At the $76 \mathrm{~dB}$ prepulse level (Figure $7 \mathrm{~B})$, the MK8o1-constant group had significantly lower PPIs than the vehicle group on every test day (all Ps < 0.044), whereas the MK-801-escalating group had significantly lower PPIs on days 1, 2, 5 and 6 (all Ps < 0.023). It also had a significantly lower PPI than the constant group on day $6(\mathrm{P}=0.012)$. At the $82 \mathrm{~dB}$ prepulse intensity level (Figure $7 \mathrm{C}$ ), the MK-801-constant group had significantly lower PPIs than the vehicle group on every test day (all Ps $<0.006)$. It also had a significantly lower PPI than the escalat-

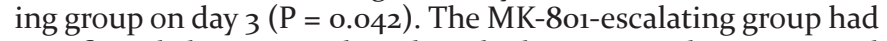
significantly lower PPIs than the vehicle group on days 2, 4, 5 and 6 (all Ps $<0.032$ ), and significantly lower PPIs than the constant group on days 5 and 6 (Ps $<0.038)$.

In comparison to day 1 of drug testing, only the MK-801-escalating group showed a significantly increased disruption of PPI at the $82 \mathrm{~dB}$ level on day $6(\mathrm{P}=0.014)$. None of the other groups showed any significant change (all Ps $>0.060$ ).

\subsubsection{Acoustic startle response (ASR)}

QUI treatment decreased startle reactivity (Figure 8A). Repeated measures ANOVAs showed a main effect of treatment $(\mathrm{F}(2$, $33)=5.366, \mathrm{P}=0.010)$, a main effect of test day $(\mathrm{F}(5,165)=4.141$, $\mathrm{P}=0.001)$ and a significant treatment $\times$ test day interaction $(\mathrm{F}(10,165)=3.633, \mathrm{P}<0.001)$. One-way ANOVAs followed by LSD post hoc test on each test day showed that the QUI-constant group had significantly lower startle amplitude than the vehicle group on every test day (all Ps < o.047). The QUI-escalating group had significantly lower startle amplitude than the vehicle group on days 2, 3, 5 and 6 (all Ps < o.035).

MK-801 treatment increased startle reactivity (Figure 8B). Repeated measures ANOVAs showed a main effect of treatment $(\mathrm{F}(2,33)=8.527, \mathrm{P}=0.001)$, a main effect of test day $(\mathrm{F}(5$, $165)=10.538, \mathrm{P}<0.001)$ and a significant treatment $\times$ test day interaction $(\mathrm{F}(10,165)=8.523, \mathrm{P}<0.001)$. One-way ANOVAs followed by LSD post hoc test on each test day showed that both MK-8o1 groups had significantly higher startle amplitude than the vehicle group on every test day (all Ps $<0.031$ ) except on day 2 when the MK-801-escalating group did not differ significantly from the vehicle group $(\mathrm{P}=0.368)$.

\section{Discussion}

Previous work on the effects of repeated administration of dopamine agonists and NMDA antagonists on PPI has reported either no change (Druhan et al., 1998; Mansbach et al., 1988; Martinez et al., 1999; Schwabe et al., 2005), sensitization (Martin-Iverson, 1999; Schulz et al., 2001; Zhang et al., 1998), or tolerance in PPI (Culm and Hammer, 2004; Feifel et al., 2002) (see (Geyer et al., 2001; Swerdlow et al., 2008) for detailed tabulations). Besides the parameter differences in PPI testing, we hypothesized that some of these differences may be attributable to differences in drug treatment paradigms, including drug doses, number of drug administrations, routes and treatment schedule, etc. The present study confirmed this hypothesis regarding dopamine agonists. For the first time, we showed that when amphetamine $5.0 \mathrm{mg} / \mathrm{kg}$ or quinpirole $0.12 \mathrm{mg} / \mathrm{kg}$ was administered in an escalating dosing regimen, both drugs still caused a disruption of PPI on the test days (days 5 and 6) when the same dose of amphetamine or
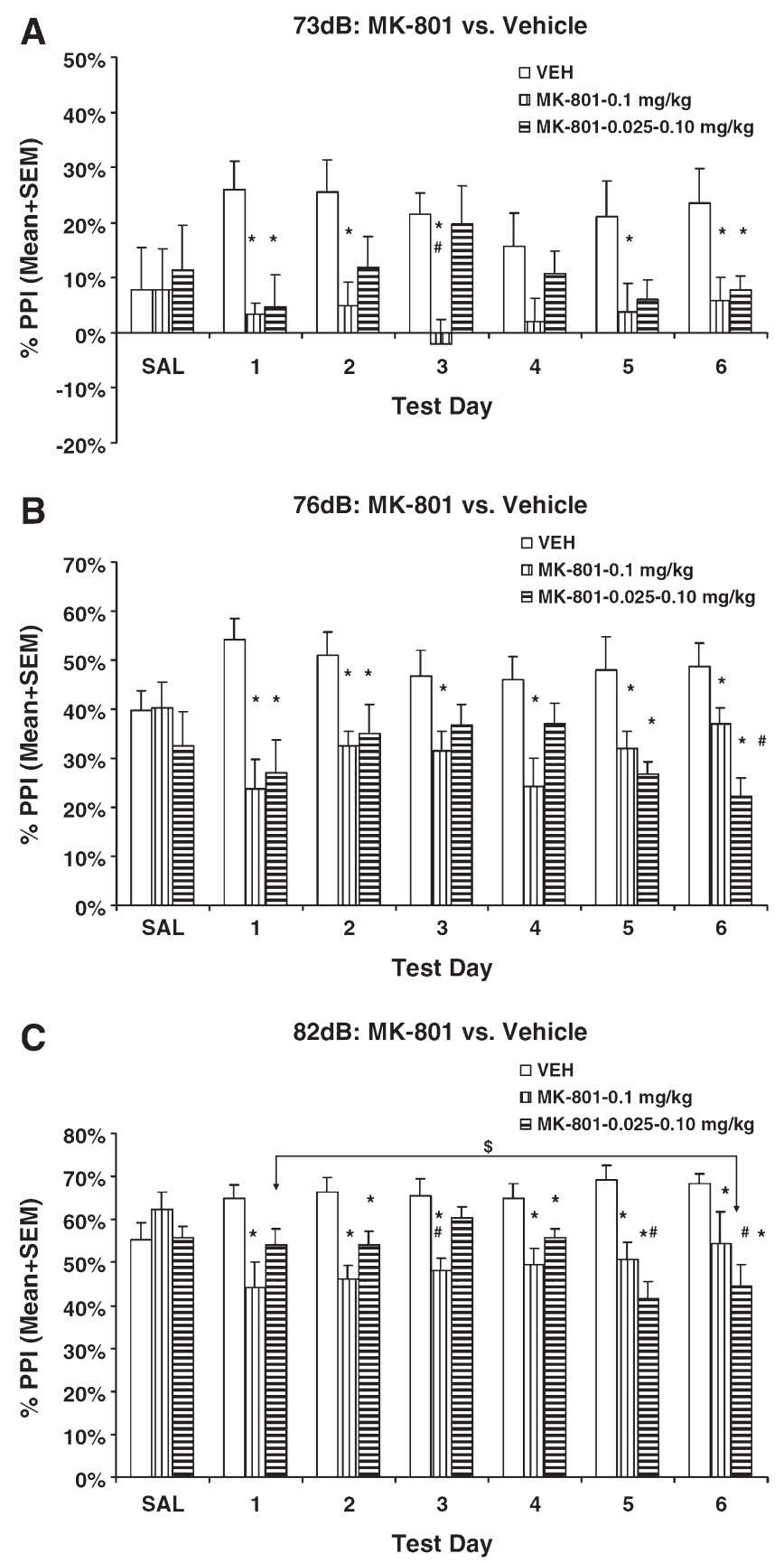

Figure 7. Effects of repeated administration of saline (VEH), constant MK-801 (o.1 mg/kg daily) or escalating MK-801 (o.025-0.10 mg/kg) for 6 consecutive days on prepulse inhibition (PPI) at the $73 \mathrm{~dB}(\mathrm{~A}), 76 \mathrm{~dB}(\mathrm{~B})$ and $82 \mathrm{~dB}(\mathrm{C})$ prepulse levels. ${ }^{*} \mathrm{P}<0.05$ significantly different from the VEH group; \# P $<0.05$ significantly different between the two quinpirole groups; $\$ \mathrm{P}<0.05$ significantly different between day 1 and day 6 .

quinpirole in the constant dosing schedule already lost its effect. We recently confirmed this general observation in a subsequent experiment using different doses of amphetamine in the two schedules. We found that rats that received an escalating amphetamine treatment (days $1-2: 1.0 \mathrm{mg} / \mathrm{kg}$; days 3-4: $2.0 \mathrm{mg} / \mathrm{kg}$, and days 5-6: $4.0 \mathrm{mg} / \mathrm{kg}$ ) exhibited PPI deficits on the last 2 days when they were tested under $4.0 \mathrm{mg} / \mathrm{kg}$ amphetamine. However, this same dose of amphetamine did not disrupt PPI on the last 2 days when it was administered in the constant schedule (days 1-6: $4.0 \mathrm{mg} / \mathrm{kg}$ ). The consistence of the findings involving different doses of amphetamine suggests the generality of such treatment regimen effect on PPI change. 


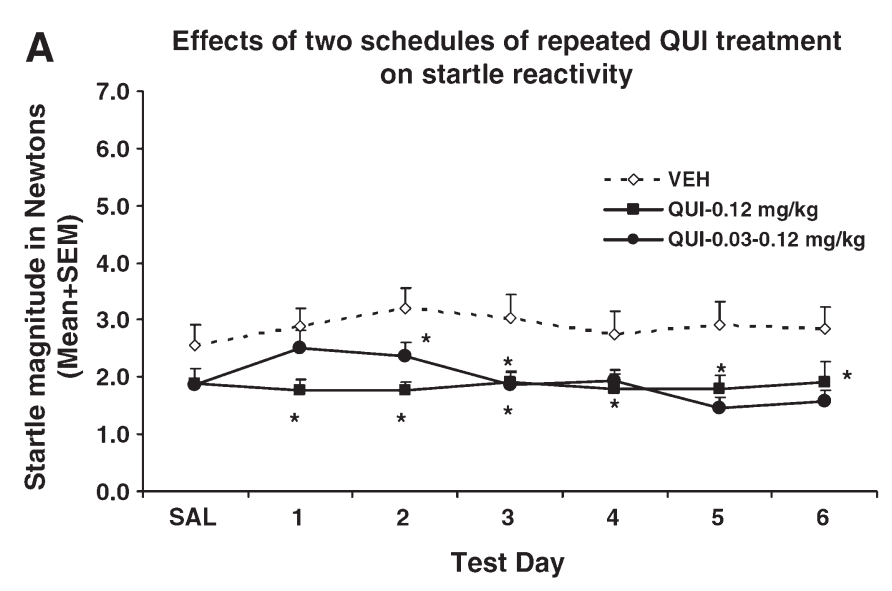

B Effects of two schedules of repeated MK-801 treatment
on startle reactivity

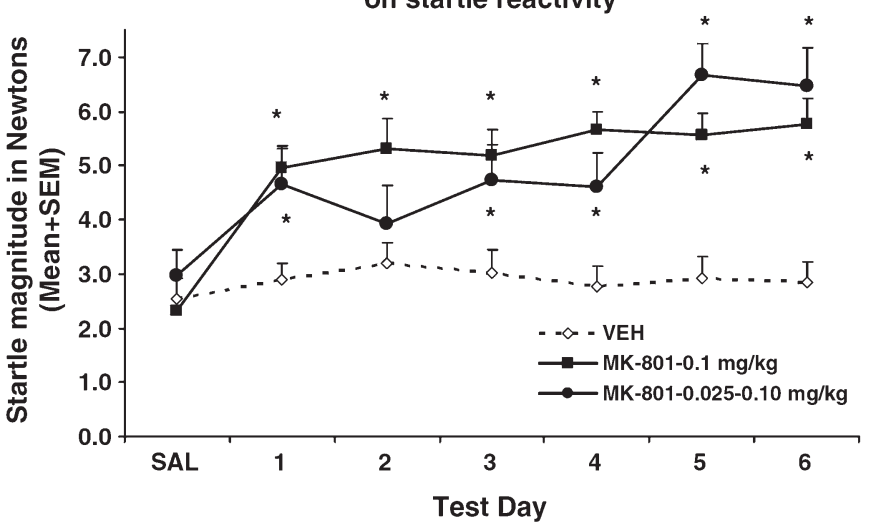

Figure 8. Effects of repeated administration of saline (VEH), quinpirole (o.12 mg/ $\mathrm{kg}$ daily or $0.03^{-0.12} \mathrm{mg} / \mathrm{kg}$ escalating throughout 6 days) (A) or MK-801 (or $0.025-0.10 \mathrm{mg} / \mathrm{kg}$ escalating throughout 6 days) (B) on startle reactivity (e.g. startle responses on $120 \mathrm{~dB}$ white noise trials). ${ }^{*} \mathrm{P}<0.05$ significantly different from the VEH group.

The constant dosing of amphetamine and quinpirole tended to produce a progressively decreased disruption on PPI (a tolerance-like effect). This finding is consistent with earlier studies demonstrating the similar tolerance development associated with repeated cocaine, amphetamine, quinpirole or apomorphine treatment (Byrnes and Hammer, 200o; Druhan et al., 1998; Feifel et al., 2002; Martin-Iverson, 1999). Interestingly, in contrast to the varying effects of different treatment schedules on PPI, amphetamine or quinpirole administered in both conditions induced a similar enhanced (a sensitization-like effect for amphetamine) or decreased (for quinpirole) effect on startle reactivity throughout the treatment days (Figures $3 \mathrm{~A}$ and $8 \mathrm{~A}$ ), suggesting a dissociation between their PPI effects and effects on startle reactivity, as they did not occur in parallel. For example, amphetamine $5.0 \mathrm{mg} /$ $\mathrm{kg}$ in the constant dosing schedule caused a significant increase in startle magnitude on day 6 , but it did not disrupt PPI. Conversely, amphetamine $5.0 \mathrm{mg} / \mathrm{kg}$ in the escalating dosing schedule did not change startle magnitude on day 6 , but it did disrupt PPI. A similar case could be made for quinpirole. These observations also suggest that the PPI tolerance effect of amphetamine was not due to a loss of drug action over time, but rather due to the specific sensitivity of PPI to this drug action. Furthermore, as rats in the constant dosing groups actually received more amphetamine or quinpirole, these results suggest that the drug dosing schedule, rather than the absolute amount of drug that an animal receives plays an important role in the development of PPI-disruptive effect of amphetamine or quinpirole. It suggests that the brain mechanisms underlying amphetamine-induced change in
PPI disruption may be different from those underlying its sensitization effect on psychomotor function (Druhan et al., 1998). The dissociation between AMPH-induced PPI disruption and psychomotor sensitization implies that sensitization-like processes and associated neuroadaptation may not be crucial in the development of a sensorimotor gating deficit as observed in patients with schizophrenia, although it is required for behavioral sensitization (Robinson and Becker, 1986).

Our finding that repeated treatment of PCP and MK-8o1 under the constant and escalating regimens at the tested dose ranges produced a stable and persistent disruption of PPI is consistent with Martinez et al. (1999) and Schwabe et al. (2005). It is inconsistent with Schulz et al. (2001), who tested MK-801 in Wistar rats. Thus, this discrepancy could be due to strain-differences between Wistar and Sprague-Dawley rats (Varty and Higgins, 1995), as the latter is more sensitive to the disruptive effect of NMDA antagonists. One may suggest that the failure to detect a sensitization effect might be due to a floor effect in the sense that PCP and MK-801 at the chosen doses already achieved a maximal PPI disruption. However, the finding that PCP at a low dose (i.e. $0.5 \mathrm{mg} / \mathrm{kg}$ ) still failed to induce a consistent increased disruption of PPI (Figure 4) argues against the floor effect explanation. Overall, our results suggest that the PPI disruption induced by PCP and MK-8o1 (at the effective dose) is generally quite stable. One caveat is that we only tested relatively low doses of PCP and MK-801 $(<2.0 \mathrm{mg} / \mathrm{kg}$ for PCP and $<0.1 \mathrm{mg} / \mathrm{kg}$ for MK-801) in this study. Other doses of PCP and MK-801 may induce different patterns of PPI disruption under different experimental conditions.

To the best of our knowledge, there is no published work that has examined the effects of escalating dose regimen on PPI throughout the course of drug treatment. Several studies that have used escalating dosing regimens only tested PPI after a period of withdrawal from a repeated treatment of amphetamine or PCP. Results are inconsistent. For example, Murphy et al. (2001a, 2001b) and Russig et al. (2003) reported no PPI disruption in rats treated with an escalating dose of amphetamine, whereas Tenn et al. $(2003,2005)$ reported a disruption of PPI in rats treated with an escalating dose of amphetamine, but not in rats treated with the same doses of PCP over the same period of time. Peleg-Raibstein et al. (2006) found that prior AMPH treatment schedule is a critical factor in inducing a long-lasting disruption of PPI. Clinical observations indicate that drug-induced psychosis is most likely to appear during the course of escalating dosage of drug administration (i.e., "binges" or "runs"), and discontinuation of drug usage usually results in a rapid decline of the psychosis, closely paralleling urine drug levels (Angrist, 1994; Davis and Schlemmer, 1980). Our finding that an escalating dose of amphetamine produces a sustained disruption in drug experienced rats seems to capture the emergence of one important psychological dysfunction (e.g. sensorimotor gating) identified in patients with schizophrenia very well. This study thus provides two important paradigms for basic researchers who are interested in developing animal models that can mimic the emerging process of sensorimotor gating deficits in patients with schizophrenia. One option is to use an escalating dosing regimen with dopamine agonists. The second is to use effective and low doses of NMDA antagonists such as PCP or MK-801. PPI disruption induced and maintained under these conditions may therefore allow us to dissect the neural and neurochemical basis of symptoms of schizophrenia.

The present study raised an interesting question: Why is an escalating dosing regimen with amphetamine or quinpirole able to induce PPI disruption when the same dose of drugs in the constant schedule is no longer effective? Neurochemical studies have showed that during the course of escalating dose treatment, extracellular dopamine and serotonin levels in the dorsal and ventral striatum progressively declined (Segal and Kuczenski, 1997), and striatal dopamine release to a challenge amphet- 
amine dose or stress was significantly enhanced, whereas dopamine release remained significantly decreased in the dorsal medial prefrontal cortex (mPFC) after a certain period of withdrawal (Hedou et al., 20o1; Paulson and Robinson, 1995; Tenn et al., 2003). This suggests that complex, time-dependent neuroadaptations in dopamine systems may lead to persistent PPI disruption under the escalating schedule. Apparently, future work is needed to elucidate the exact neurochemical mechanisms.

Finally, we should point out that other factors may also influence a drug's effect on PPI, in addition to the drug administration regimen and PPI parameters. One such factor is whether drug treatment is paired with the PPI testing environment during the repeated drug treatment period. Since repeated PPI testing involves repeated presentation of startle stimulus which is a mild stressor by itself, repeated daily testing could conceivably alter drug effects on PPI over time by altering the impacts of emotional responses (e.g. fear) on PPI performance. In the literature, a tolerance-like or sensitization-like disruption on PPI has often been found under a condition when the drug injections were paired with repeated PPI testing (Culm et al., 2004; Feifel et al., 2002; Martin-Iverson, 1999; Schulz et al., 2001; Zhang et al., 1998), whereas repeated drug treatment that was not paired with PPI testing did not result in PPI change (Byrnes and Hammer, 2000; Druhan et al., 1998; Mansbach et al., 1988; Martinez et al., 1999). It has therefore been suggested that repeated effects of drug treatment on PPI-disruption might be revealed only in the presence of a drug-associated context (Feifel et al., 2002; Martin-Iverson, 1999; Russig et al., 2003). Our findings with amphetamine and quinpirole are consistent with this explanation. This idea fits well with the proposition that psychomotor sensitization is context-specific, and under certain conditions, psychomotor sensitization can only be detected in a specific environment where repeated drug administration occurs (Anagnostaras and Robinson, 1996; Robinson and Becker, 1986). However, the impact of this factor may be limited to dopamine agonists because we did not observe any change with NMDA antagonists (e.g. PCP and MK-801). In light of the evidence that drug-environment pairing is important for the induction of psychomotor sensitization for dopamine agonists (Anagnostaras and Robinson, 1996), the lack of impact of such a factor on amphetamineinduced PPI change further suggests that the neural basis responsible for amphetamine-induced change in PPI disruption is likely different from those underlying its psychomotor sensitization (Druhan et al., 1998). Future work should address this issue further by examining how this factor interacts with other factors (e.g. PPI testing parameters and drug dosing regimens) in determining the PPI-disruptive effect. This approach will enhance our ability to develop more reliable animal models based on pharmacological treatment.

Acknowledgments - We thank Professor Ronald Hammer Jr. for the help on PPI procedure. We also thank Mr. Tao Sun for his technical support and Ms. Heidi Gonzalez for her editorial work. This study was funded in part by a support from the Nebraska Tobacco Settlement Biomedical Research Development Funds, and by a research grant (o7R1775) from the Stanley Medical Research Institute to ML.

\section{References}

Anagnostaras SG, Robinson TE. Sensitization to the psychomotor stimulant effects of amphetamine: modulation by associative learning. Behav Neurosci 1996;110: 1397-414.

Angrist B. Amphetamine psychosis: clinical variations of the syndrome. In: Cho A, Segal D, editors. Amphetamine and its analogues. San Diego: Academic Press; 1994. p. 387-414.

Bell DS. Comparison of amphetamine psychosis and schizophrenia. Br J Psychiatry 1965;111:701-7.

Braff DL, Geyer MA. Sensorimotor gating and schizophrenia. Human and animal model studies. Arch Gen Psychiatry 1990;47:181-8.
Braff DL, Geyer MA, Light GA, Sprock J, Perry W, Cadenhead KS, et al. Impact of prepulse characteristics on the detection of sensorimotor gating deficits in schizophrenia. Schizophr Res 2001;49:171-8.

Byrnes JJ, Hammer RP. The disruptive effect of cocaine on prepulse inhibition is prevented by repeated administration in rats. Neuropsychopharmacology 2000;22:551-4.

Culm KE, Hammer Jr RP. Recovery of sensorimotor gating without G protein adaptation after repeated D2-like dopamine receptor agonist treatment in rats. J Pharmacol Exp Ther 2004;308:487-94.

Culm KE, Lugo-Escobar N, Hope BT, Hammer Jr RP. Repeated quinpirole treatment increases cAMP-dependent protein kinase activity and CREB phosphorylation in nucleus accumbens and reverses quinpirole-induced sensorimotor gating deficits in rats. Neuropsychopharmacology 2004;29:1823-30.

Davis JM, Schlemmer Jr FP. The amphetamine psychosis. In: Caldwell J, editor. Amphetamines and related stimulants: chemical, biological, clinical and social aspects. Boca Raton, FL: CRC Press; 1980. p. 161-73.

Druhan JP, Geyer MA, Valentino RJ. Lack of sensitization to the effects of D-amphetamine and apomorphine on sensorimotor gating in rats. Psychopharmacology (Berl) 1998;135:296-304.

Ellinwood Jr EH, Sudilovsky A, Nelson LM. Evolving behavior in the clinical and experimental amphetamine (model) psychosis. Am J Psychiatry 1973;130:1088-93.

Feifel D, Priebe K, Johnstone-Miller E, Morgan CJ. Sensorimotor gating effects produced by repeated dopamine agonists in a paradigm favoring environmental conditioning. Psychopharmacology (Berl) 2002;162:138-46.

Fletcher PJ, Tenn CC, Rizos Z, Lovic V, Kapur S. Sensitization to amphetamine, but not PCP, impairs attentional set shifting: reversal by a $\mathrm{D}_{1}$ receptor agonist injected into the medial prefrontal cortex. Psychopharmacology (Berl) 2005;183:190-200.

Geyer MA, Braff DL. Startle habituation and sensorimotor gating in schizophrenia and related animal models. Schizophr Bull 1987;13:643-68.

Geyer MA, Krebs-Thomson K, Braff DL, Swerdlow NR. Pharmacological studies of prepulse inhibition models of sensorimotor gating deficits in schizophrenia: a decade in review. Psychopharmacology (Berl) 2001;156:117-54.

Griffith JD, Cavanaugh J, Held J, Oates JA. Dextroamphetamine. Evaluation of psychomimetic properties in man. Arch Gen Psychiatry 1972;26:97-100.

Hedou G, Homberg J, Feldon J, Heidbreder CA. Expression of sensitization to amphetamine and dynamics of dopamine neurotransmission in different laminae of the rat medial prefrontal cortex. Neuropharmacology 2001;40:366-82.

Janowsky DS, Risch C. Amphetamine psychosis and psychotic symptoms. Psychopharmacology (Berl) 1979;65:73-7.

Javitt DC, Zukin SR. Recent advances in the phencyclidine model of schizophrenia. Am J Psychiatry 1991;148:1301-8.

Mansbach RS, Geyer MA. Effects of phencyclidine and phencyclidine biologs on sensorimotor gating in the rat. Neuropsychopharmacology 1989;2:299-308.

Mansbach RS, Geyer MA, Braff DL. Dopaminergic stimulation disrupts sensorimotor gating in the rat. Psychopharmacology (Berl) 1988;94:507-14.

Martin-IversonMT.Does sensitization occur to prepulse inhibition of the startle reflex effects of repeated apomorphine treatments in rats? J Psychopharmacol 1999;13:261-73.

Martinez V, Parikh V, Sarter M. Sensitized attentional performance and Fosimmunoreactive cholinergic neurons in the basal forebrain of amphetaminepretreated rats. Biol Psychiatry 2005;57:1138-46.

Martinez ZA, Ellison GD, Geyer MA, Swerdlow NR. Effects of sustained phencyclidine exposure on sensorimotor gating of startle in rats. Neuropsychopharmacology 1999;21:28-39.

Murphy CA, Di Iorio L, Feldon J. Effects of psychostimulant withdrawal on latent inhibition of conditioned active avoidance and prepulse inhibition of the acoustic startle response. Psychopharmacology (Berl) 2001a;156:155-64. vMurphy CA, Fend M, Russig H, Feldon J. Latent inhibition, but not prepulse inhibition, is reduced during withdrawal from an escalating dosage schedule of amphetamine. Behav Neurosci 2001b;115:1247-56. 
Nestler EJ. Molecular neurobiology of addiction. Am J Addict 2001;10:201-17.

Paulson PE, Robinson TE. Amphetamine-induced time-dependent sensitization of dopamine neurotransmission in the dorsal and ventral striatum: a microdialysis study in behaving rats. Synapse 1995;19:56-65.

Peleg-Raibstein D, Sydekum E, Feldon J. Differential effects on prepulse inhibition of withdrawal from two different repeated administration schedules of amphetamine. Int J Neuropsychopharmacol 2006;9:737-49.

Robinson TE, Becker JB. Enduring changes in brain and behavior produced by chronic amphetamine administration: a review and evaluation of animal models of amphetamine psychosis. Brain Res 1986;396:157-98.

Russig H, Murphy CA, Feldon J. Prepulse inhibition during withdrawal from an escalating dosage schedule of amphetamine. Psychopharmacology (Berl) 2003;169:340-53.

Schulz B, Fendt M, Pedersen V, Koch M. Sensitization of prepulse inhibition deficits by repeated administration of dizocilpine. Psychopharmacology (Berl) 2001;156: 177-81.

Schwabe K, Brosda J, Wegener N, Koch M. Clozapine enhances disruption of prepulse inhibition after sub-chronic dizocilpine- or phencyclidine-treatment in Wistar rats. Pharmacol Biochem Behav 2005;80:213-9.

Segal DS, Geyer MA, Schuckit MA. Stimulant-induced psychosis: an evaluation of animal methods. Essays Neurochem Neuropharmacol 1981;5:95-129.

Segal DS, Kuczenski R. An escalating dose "binge" model of amphetamine psychosis: behavioral and neurochemical characteristics. J Neurosci 1997;17:2551-66.
Segal DS, Mandell AJ. Long-term administration of D-amphetamine: progressive augmentation of motor activity and stereotypy. Pharmacol Biochem Behav 1974;2:249-55.

Simon SL, Richardson K, Dacey J, Glynn S, Domier CP, Rawson RA, et al. A comparison of patterns of methamphetamine and cocaine use. J Addict Dis 2002;21:35-44.

Swerdlow NR, Braff DL, Geyer MA. Animal models of deficient sensorimotor gating: what we know, what we think we know, and what we hope to know soon. Behav Pharmacol 2000;11:185-204.

Swerdlow NR, Weber M, Qu Y, Light GA, Braff DL. Realistic expectations of prepulse inhibition in translational models for schizophrenia research. Psychopharmacology (Berl) 2008;199:331-88.

Tenn CC, Fletcher PJ, Kapur S. Amphetamine-sensitized animals show a sensorimotor gating and neurochemical abnormality similar to that of schizophrenia. Schizophr Res 2003;64:103-14.

Tenn CC, Kapur S, Fletcher PJ. Sensitization to amphetamine, but not phencyclidine, disrupts prepulse inhibition and latent inhibition. Psychopharmacology (Berl) 2005;180:366-76.

Varty GB, Higgins GA. Examination of drug-induced and isolation-induced disruptions of prepulse inhibition as models to screen antipsychotic drugs. Psychopharmacology (Berl) 1995;122:15-26.

Zhang J, Engel JA, Soderpalm B, Svensson L. Repeated administration of amphetamine induces sensitisation to its disruptive effect on prepulse inhibition in the rat. Psychopharmacology (Berl) 1998;135:401-6. 